\title{
EDUCADOR SOCIAL E AMBIENTAL: PROTAGONISTA NA FORMAÇÃO DE UMA REDE DE PROTEÇÃO PARA CRIANÇAS E ADOLESCENTES VÍTIMAS DE ABUSO SEXUAL
}

\author{
Ângela Torma Pietro ${ }^{1}$; Eliane Lima Piske ${ }^{2}$; Maria Angela Mattar Yunes ${ }^{3}$
}

\begin{abstract}
RESUMO
Cooperação, diálogo e ações interdisciplinares são essenciais para a existência de uma rede de proteção para crianças e adolescentes vítimas de abuso sexual. Com este propósito foi criado o Programa de Intervenção Psicoeducacional, visando formar educadores sociais e ambientais para atender e garantir a proteção integral às vítimas. Contou com a participação de 50 membros da rede intersetorial de um município do extremo Sul do Brasil. Teve por base teórica e metodológica a Bioecologia de Desenvolvimento Humano (BRONFENBRENNER, 2011). A análise dos dados identificou a inexistência de um trabalho em rede, evidenciando a necessidade de uma capacitação permanente para potencializar práticas dialógicas, o que é urgente para construir conhecimentos e romper com a dicotomia entre reflexão e ação.
\end{abstract}

Palavras-chave: Abuso Sexual; Rede de Atendimento; Educador Social e Ambiental.

\begin{abstract}
Cooperation, dialogue and interdisciplinary actions are essential for the existence of a network of protection for children and teenagers who are sexual abuse victims. With this purpose the Psychoeducational Intervention Program was created aiming to edify social and environmental educators to attend and guarantee integral protection to the victims. It was attended by 50 members of the intersectoral network of a city in the extreme south of Brazil. It was based on the theoretical and methodological Urie Bronfenbrenner's Human Development Bioecology (BRONFENBRENNER, 2011). The analysis of the data identified the lack of a network evidencing the demand of permanent training to potentialize dialogic practices, which is urgent to build knowledge and to break with the dichotomy between reflection and action.
\end{abstract}

Keywords: Sexual abuse; Service network; Social and environmental educator.

\section{INTRODUÇÃO}

A degradação da natureza, a pobreza extrema, a violência e o desrespeito aos direitos humanos são grandes propulsores da crise sócio-ecológica-ambiental

\footnotetext{
${ }^{1}$ Historiadora, Advogada, Doutora em Educação Ambiental pela Universidade Federal do Rio Grande PPGEA/FURG, Professora no Curso de Direito da Faculdade Anhanguera do Rio Grande, RS, colaboradora do Centro de Referência em Apoio as Famílias- CRAF/FURG. Contato: angela.torma@gmail.com.

2 Pedagoga, Doutoranda do Programa de Pós-Graduação em Educação Ambiental pela Universidade Federal do Rio Grande - PPGEA/FURG, colaboradora do Centro de Referência em Apoio as FamíliasCRAF/FURG, Bolsista CAPES. Contato: e.nanny@ hotmail.com.

${ }^{3}$ Psicóloga, Doutora em Educação, Professora no Programa de Pós-Graduação em Psicologia da Universidade Salgado de Oliveira, Niterói, RJ, Professora colaboradora no Programa de Pós-Graduação em Educação na Universidade La Salle, Unilasalle, Canoas, RS, Professora colaboradora no Programa de Pós-Graduação em Educação Ambiental da Universidade Federal do Rio Grande- FURG. Contato: mamyunes@yahoo.com.br.
} 
(MACHADO; CALLONI; ADOMILLI, 2016) que assola nossa sociedade. Neste sentido, a Educação Ambiental contribui na formação de diálogos e reflexões sobre estas realidades, através de uma visão global, crítica e reflexiva sobre a complexidade destes fenômenos naturais, sociais e culturais (SANTOS; SATO, 2001).

No que tange à violência, esta se manifesta de diferentes formas. Uma das suas mais perversas expressões é o abuso sexual contra crianças e adolescentes, que impõe à vítima todas as formas de violações de direitos. Assim, compreender seus condicionantes e faces constitui tarefa essencial para a formação de uma rede de proteção, o que exige de todos os envolvidos um trabalho articulado, responsável e cooperativo. Evidenciando a importância da Educação Ambiental no que concerne à promoção da cooperação e do diálogo entre profissionais e instituições, tendo como finalidade gerar melhores modos de vida e respeitar os direitos de todos os indivíduos (DIAS, 2004). Sendo necessário o profissional se reconhecer como um Educador Social e Ambiental: um agente sócio-ecológico-ambiental consciente do seu papel, da sua responsabilidade e de sua ética sendo e estando o dever e o cuidado atrelados as suas ações.

É necessário ter uma visão inter/transdisciplinar do atendimento, em especial nos casos de violência sexual onde, o sujeito ecológico (CARVALHO; ALMEIDA, 2003) seja e esteja em sintonia com seus pares. A atuação não pode e não deve ser individual é necessário desenvolver um trabalho conjunto, sistêmico e interdisciplinar que envolva todas as instituições que atuam nos casos de violência sexual contra a criança e/ou o adolescente.

Assim, entendemos "rede" como uma expressão que indica um entrelaçamento de fios unidos por nós e que formam uma malha regular ou irregular, considerando os nós metaforicamente às instituições de atendimento, todas elas inter-relacionadas e atuando de forma sistêmica (PIETRO, 2013). Duarte e Klaus (2008) compreendem uma rede como uma estrutura social formada por pessoas ou organizações que se atrelam por objetivos comuns. Uma das suas especificidades é a possibilidade de interlocuções não hierarquizadas entre os seus partícipes. Assim, entendemos que uma rede implica comunicação e troca de informações, o que em um âmbito maior pode significar um fortalecimento das sociedades. 
Acredita-se que esta articulação não deve estar restrita ao interior de cada serviço, mas deve também abarcar os diferentes serviços que prestam atendimento a esse tipo de clientela, de modo a conformar uma rede integrada de apoio (SOUZA; ASSIS; ALZU, 2002, p.115).

Defende-se um trabalho interdisciplinar onde ocorre integração, cooperação e colaboração entre os serviços envolvidos. Neste sentido, o programa de intervenção que esse estudo apresenta foi direcionado para potencializar o diálogo entre os profissionais de diferentes serviços e buscar estratégias conjuntas de prevenção e intervenção nos casos de violência sexual contra crianças e adolescentes. Foram metas do presente estudo: mobilizar a criação de uma rede de proteção para o atendimento e priorizar os direitos das crianças e dos adolescentes vitimizados, através da formação de educadores sociais e ambientais. O programa que aqui será discutido foi desenvolvido a partir de eixos temáticos derivados da análise do mapeamento do atendimento às crianças e aos adolescentes vítimas de abuso sexual, numa cidade do extremo sul do Rio Grande do Sul. Foi elaborado a partir da inspiração em uma proposta semelhante desenvolvida por Pietro (2007) em uma escola de ensino fundamental junto a professores da rede pública (PIETRO; YUNES; LIMA, 2014).

Sabe-se que a violência sexual é uma das formas mais complexas de agressão e que merece atenção de toda a sociedade. As normas de respeito mútuo estabelecidas pelas sociedades civilizadas deveriam permear todas as relações sociais. Entretanto, nos casos de violência sexual contra crianças e adolescentes tais preceitos são totalmente desrespeitados e emerge uma forma de agressão que rompe com qualquer atitude civil, declarando a barbárie com a explícita violação de direitos de um ser vulnerável. É indiscutível que esses episódios, quando comprovados, não se dão de forma legitimada, mas sim pela imposição, exercida pela negação ou pela ameaça a vitima (FALEIROS, 2005). Neste entendimento, conforme Azevedo e Guerra (1989, p.42) “o abuso sexual pode ser compreendido como uma ação intencional praticada por um adulto que tem como objetivo obter estimulação sexual ou estimular sexualmente uma criança ou um adolescente".

A definição acima denota a complexidade de um tema que não pode ser compreendido de forma isolada e/ou fragmentada, pois envolve dimensões de diferentes ordens: históricas (evolução da própria sociedade); culturais (etnia, gênero e raça); 
sociais (relações familiares e convívio na sociedade); econômicas (relacionada à perda do provedor quando ocorre a revelação); sexuais (sedução e culpabilização); poder (força física e segredo); e, ainda, psicológicas (relacionadas ao medo e ao trauma gerado por esta modalidade de violência) (FALEIROS, 2005). Não é possível compreender a violência sexual a partir de um único aspecto, por isso, a percebemos como um fenômeno complexo, sendo necessário compreender a multiplicidade de dimensões a ela associadas (PIETRO, 2013).

A abordagem bioecológica de desenvolvimento humano (BRONFENBRENNER, 2011) oferece o suporte para compreender a complexidade do abuso sexual numa perspectiva sistêmica e bioecológica. Assim, a criança e/ou adolescente vitimizado e que, por sua condição, apresenta-se vulnerável ${ }^{4}$ é compreendida por meio de sua inserção em múltiplos contextos, nomeadamente: microssistema, mesossistema, o exossistema e o macrossistema (BRONFENBRENNER, 1996; BRONFENBRENNER; MORRIS, 1998).

O primeiro microssistema que a criança vivencia é a família, espaço que deveria ser de amor e carinho. Porém, em casos de práticas de violência sexual o espaço da casa torna-se de sofrimento e traumas. Outros microssistemas na vida das crianças e dos adolescentes, de acordo com a abordagem ecológica são: a escola, o posto de saúde, a igreja e outros espaços onde, se transita e se estabelece relações face a face com frequência regular. Já o mesossistema é compreendido como as inter-relações entre os microssistemas, sejam a relação família-escola; família-posto de saúde, dentre outros locais.

O exossistema é as influências de contextos não frequentados diretamente pela criança e/ou adolescente, mas que têm impacto no seu desenvolvimento e decisões, como exemplo, o trabalho dos pais ou a direção da escola. O macrossistema inclui todos os outros sistemas anteriores que formam os valores sociais, culturais, históricos, políticos, econômicos, dentre outros que contribuem para as mudanças e as crenças da sociedade como um todo. Um exemplo macrossistêmico é a percepção de "criança

\footnotetext{
${ }^{4}$ As expressões "crianças em situação de risco" e "crianças em situação de vulnerabilidade" não são sinônimos, a diferença é que em condições vulneráveis o risco ainda não é eminente e nas condições de risco sim, embora existam aproximações, a vulnerabilidade opera quando o risco está presente, caso contrário, sem o risco a vulnerabilidade não faz e não é efeito (YUNES; SZYMANSKI, 2005).
} 
abusada" nas diferentes sociedades (PIETRO; YUNES; LIMA, 2014) que, afeta de forma significativa o microssistema familiar e estabelece inter-relações e conexões com os demais microssistemas, por onde a criança transita.

Nesses casos, a complexidade é exatamente no sentido de se entender que, após, a denúncia e/ou revelação da violência sexual é importante pensar na criança ou adolescente e nas intervenções que não gerem revitimização durante o atendimento em rede. É preciso priorizar um trabalho inter-transdisciplinar onde a proteção integral à vítima se coloca acima das questões relacionadas ao processo legal e da punição do abusador.

Deve-se ressaltar que o desconhecimento do profissional acerca da relevância de seu papel no escopo de um trabalho conjunto e interdisciplinar pode potencializar o trauma causado pela violência. Para tanto, é necessário percorrer os caminhos e/ou as portas de entrada que recebem as denúncias, bem como compreender quais os mecanismos e aportes feitos pelos diversos profissionais que atendem a vítima, a família e o abusador nesse primeiro sensível momento. Sabe-se que na maioria dos municípios, um número elevado de instituições podem atuar primariamente, tais quais: Conselho Tutelar (CT); Ministério Público (MP); Judiciário; Polícia Civil (PC), dentre outras. E, ainda na tentativa de punir o abusador, essas instituições requerem que a criança e/ou adolescente relate com detalhes a situação que vivenciou. Reviver a violência na repetida narrativa das dores sentidas na condição de abusado pode levar a um sofrimento e uma revitimização que acentua o trauma da vítima que pode sentir-se ainda mais frágil e desamparada (PIETRO; YUNES; LIMA, 2014).

Algumas classes profissionais sociais devem estar especialmente preparadas para estas funções, pois, além de seus papéis lhes colocarem frente a frente com estas ocorrências, a legislação os obriga a efetuar a notificação sob risco de punição administrativa, se não o fizerem. Conforme o art. 245 do Estatuto da Criança e do Adolescente (ECA) estarão sujeitos a multa de três a vinte salários de referência: os médicos, os professores e/ou responsáveis por estabelecimento de atenção à saúde e a educação que, deixarem de comunicar aos órgãos competentes os casos de abuso e maus tratos contra crianças e adolescentes (BRASIL, 2017). 
Neste sentido, uma visão sistêmica desta modalidade de violência pode permitir um trabalho em rede, no qual todos os profissionais envolvidos tenham um único objetivo: a proteção integral da vítima, por meio da realização de um trabalho dialógico e compromissado. Preocupa-nos constatar que, em muitos casos de abuso sexual, as vítimas convivem por tempo indeterminado com as situações de risco. Situações de risco são compreendidas como um conjunto de eventos e processos negativos que se apresentam na vida da pessoa em desenvolvimento e aumentam a probabilidade de ocorrerem problemas físicos, psicológicos, sociais e emocionais (YUNES; SZYMANSKI, 2005; YUNES; MIRANDA; CUELLO, 2004).

Para contrapor-se aos mecanismos de risco que esta grave questão suscita, é preciso gerar fatores de proteção, que possam transformar esta situação. Caso a família seja a responsável por expor a criança à violência, cabe aos demais microssistemas que formam a rede de atendimento social, por exemplo, a escola ou o posto de saúde atuar de forma protetiva, para impedir que o abuso perdure. Muitos pesquisadores buscaram compreender o fenômeno do abuso sexual, realizando diversos estudos sobre a dinâmica do abuso nas famílias e participação das vítimas antes e após a revelação (PELISOLI; TEODORO; DELL'AGLIO, 2011; PELISOLI, 2008; SANTOS, 2013; PINCOLINI; HUTZ, 2012), sobre os abusadores e processos criminais (MOURA; KOLLER 2008), com as famílias após o término do processo judicial de culpabilização do abusador (PINCOLINI; HUTZ, 2012), bem como sobre o atendimento da vítima (HABIGZANG et al., 2005; MARQUES; MAIO, 2007; PELISOLI, 2008; FARAJ; SIQUEIRA， 2014; FLORENTINO, 2015) e trazendo o olhar dos profissionais acerca da Rede de Proteção (FARAJ; SIQUEIRA; ARPINI, 2016).

Porém, apesar das contribuições, ainda persistem a carência de estudos que ofereçam uma visão globalizada do atendimento e que proponha pensar a efetivação de uma rede de proteção para a criança e o adolescente vitimizado, tendo como foco a garantia dos direitos fundamentais estipulados no Estatuto da Criança e do Adolescente (BRASIL, 2017). Pensando em questões macrossistêmicas, a miséria, o desemprego e o uso de drogas são apontados como fatores de risco para a ocorrência do abuso sexual (HABIGZANG et al., 2005). Na verdade, é preciso considerar uma gama de fatores 
sociais, tais como: ausência de segurança pública, baixo número de instituições de apoio com políticas públicas claras e eficientes e o abandono social das famílias brasileiras.

Especificamente, a pobreza e/ou a condição de miséria extrema não são linearmente determinantes para o abuso sexual em famílias, pois há casos onde o abuso ocorre sem que haja estes indicadores. A violência sexual no Brasil (e em outros lugares do mundo) não é um fenômeno restrito às camadas populares, mas envolve pessoas de todas as classes sociais, de diversos credos e áreas profissionais (PIETRO, YUNES; LIMA, 2014). Atravessa todas as camadas sociais, etnias, crenças e culturas e atinge na sua maior expressão, o gênero feminino (HABIGZANG et al., 2005), mas há muitos meninos vítimas de violência sexual (HOHENDORFF, et al., 2013). Assim, percebe-se a necessidade de realizar intervenções que possam detectar e intervir de forma significativa e potencialmente protetiva para garantir a proteção de crianças e/ou adolescentes vítimas de violência sexual.

\section{MÉTODO}

Foi realizada uma pesquisa quanti-qualitativa desenvolvida em duas etapas:

$1^{\text {a }}$. Mapeamento da rede intersetorial com o fim de identificar o fluxo de atendimento nos casos de abuso sexual;

$2^{a}$. Elaboração e realização do Programa Piloto de Intervenção Psicoeducacional “Curso Reflexão e Diálogo sobre violência sexual contra crianças e adolescentes: por uma ação integrada no território" com os profissionais que atendem as crianças/adolescentes, familiares e agressores.

Durante a primeira etapa foi aplicado um questionário semi-estruturado com a participação de 422 profissionais, visando compreender ecologicamente o atendimento à criança e ao adolescente vítima de abuso sexual, às famílias e ao abusador. Foram observados os passos seguidos por todas as instituições e como acontece a relação entre elas. As análises da primeira fase permitiram compreender o fluxo de atendimento, as interlocuções existentes entre as instituições e ainda perceber as dificuldades e problemas existentes que podem causar ou potencializar a revitimização da vítima.

Realizada a análise desta primeira fase, foi elaborado e aplicado o Programa de Intervenção Psicoeducacional, junto aos profissionais com vistas a construir estratégias 
de prevenção nos casos de violência sexual contra crianças e adolescentes. O programa foi desenvolvido a partir de eixos temáticos divididos em oito módulos, sendo eles:

Módulo I - Direitos Humanos: Violações. Abuso Sexual Infantil: conceitos e indicadores; Módulo II - Incesto x Pedofilia x Abuso Sexual; Módulo III - Questões Legais: Constituição Federal (CF), Código Penal (CP) e ECA; Módulo IV - Famílias e violência; Módulo V - Denúncia e Rede de Proteção; Módulo VI - Responsabilidade do Educador Social e Ambiental; Módulo VII - Plano de Ação; Módulo VIII - Plano de Intervenção. Sendo que, os módulos VII e VIII foram a elaboração coletiva e efetiva de um plano de ação e intervenção para os casos de violência sexual contra as crianças e os adolescentes.

A aplicação dos módulos seguiu o modelo experiencial. Os programas que funcionam neste modelo não pretendem apenas informar teorias ou técnicas, mas trabalhar com o cenário cotidiano de cada profissional, de forma que sejam capazes de reconstruir seus conhecimentos prévios e atuarem coletivamente (MARTÍN et al., 2009). Ao contrário de outros modelos, leva em consideração as crenças prévias, suas expectativas e opiniões. E é a partir desse conhecimento experiencial que se constroem novas aprendizagens (MÁIQUEZ et al., 2000), especialmente nos programas grupais, onde existem um compartilhar de experiências. É um tipo de modelo que convida à ação e à reflexão ao fortalecer o que já estava sendo pensado, ou ainda, ao ajudar a (re)pensar as questões que são mais pontuais e que requerem compreensão e transformação (MARTIN, 2005).

Foi realizado um paralelo sobre a filosofia de base do modelo experiencial com a Bioecologia do Desenvolvimento Humano, que integra o tempo, o processo, a pessoa e o contexto (BRONFENBRENNER, 2011), estando e permanecendo aliados pelo/com os alicerces ideológicos do pensamento freiriano, já que este modelo de educação experiencial tem por base as atividades de diálogo e reflexão, a partir dos próprios conhecimentos, das experiências, dos valores, das tradições e das crenças (YUNES, 2012).

Quanto à escolha do lugar onde foi realizado o Programa, adveio por ser em local estratégico, um dos municípios do Estado do Rio Grande do Sul, contemplado pelo Programa de Prevenção a Violência (PPV) do governo do Estado do Rio Grande 
do Sul, com a justificativa de um mapeamento situacional, elaborado no município, que apresentou os problemas e a vulnerabilidade social enfrentada em bairros da periferia da cidade. Assim, foi usado como critério de inclusão as instituições que fizeram parte desta área que participaram da primeira fase do estudo, para que a formação de uma rede de atendimento integrada pudesse efetivamente proporcionar uma melhoria da qualidade de vida das crianças e dos adolescentes destas comunidades.

Como se tratou de um programa piloto, disponibilizou-se 50 vagas que foram preenchidas na sua integralidade, sendo formada uma lista de espera por profissionais, tendo em vista o número elevado de pessoas interessadas. Foi elaborado material didático para os participantes do curso. Os profissionais atuavam junto à área do PPV eram representantes das seguintes instituições: Conselho Tutelar- CT (sete conselheiros representantes da Conselho II e III); Brigada Militar (dois policiais militares); Estratégia Saúde da Família (seis agentes comunitários de saúde, um assistente social, 17 educadores sociais e dois enfermeiros); Centro de Referência Especializado em Assistência Social- CREAS (dois psicólogos, um assistente social e uma secretária); Centro de Referência da Assistência Social - CRAS (uma assistente social e uma secretária); três escolas (cinco professores); Rede Família (uma educadora social e duas assistentes sociais) e uma representante de instituição não governamental (uma coordenadora). Destes, $98 \%$ são do sexo feminino e $2 \%$ do sexo masculino. As idades variam de 23 anos a 60 anos de idade. Quanto ao estado civil, 44\% são casados, 10\% são divorciados, $26 \%$ são solteiros e $20 \%$ vivem em união estável. Quanto ao tempo de trabalho na instituição, seguimos a seguinte organização: menos de 1 ano; de 1 a 3 anos; de 3 a 5 anos; de 5 a 10 anos e, mais de 10 anos. Assim, 48\% dos profissionais trabalham a menos de 1 ano no local, 16\% trabalham de 1 a 3 anos, 12\% trabalham de 3 a 5 anos, 4\% trabalham de 5 a 10 ano, 10\% trabalham mais de 10 anos e $10 \%$ não responderam.

Para análise dos dados qualitativos obtidos, foram utilizados os princípios da grounded-theory (STRAUSS; CORBIN, 1990). A grounded-theory foi cogitada, neste caso, por oferecer condições de descoberta de uma teoria a partir dos dados coletados (YUNES; SZYMANSKI, 2005). O pesquisador que faz uso da grounded-theory tem possibilidade de organizar uma grande quantidade de dados qualitativos, neste caso, 
obtidos a partir das respostas abertas dos questionários, em códigos, subcategorias e categorias. Os rigores dos procedimentos desta forma de análise possibilitaram certa "descontaminação" das idéias teóricas e hipóteses previamente elaboradas para a realização do seu estudo. A grounded-theory com o uso do software N-VIVO foram utilizados para organizar e implementar a qualidade das análises quantitativas e qualitativas. É uma abordagem particularmente válida para campos de pesquisa pouco conhecidos, mas potentes para análise dos dados.

\section{RESULTADOS E DISCUSSÃO}

A primeira fase do estudo mapeou e retratou o trabalho institucional e algumas percepções dos profissionais que atendem as crianças e/ou adolescentes, as famílias e os agentes responsáveis pelo processo legal de culpabilização do abusador. A análise dos dados, deste primeiro grande momento, apontou a existência de um trabalho ainda fragmentado e com dificuldades de interlocuções entre os serviços, apesar da maioria dos participantes concordarem com a existência de uma rede.

No entanto, apontaram que a rede de atendimento não opera pela falta de elementos essenciais que a constituem, entre elas a carência de informação compartilhada, a falta de diálogo e a prática de ações isoladas, fragmentadas e burocratizadas por encaminhamento de documentos e papéis. Percebemos que alguns profissionais (um terço na maioria dos aspectos) possuem esta consciência, principalmente quando apontam suas dificuldades e medidas preventivas nos casos. Assim, foi pensada a segunda fase deste estudo para proporcionar aos participantes da primeira fase um espaço concreto de diálogo e reflexão, onde os profissionais se encontrassem e juntos pudessem pensar no trabalho realizado e de que forma o mesmo poderia ser ou não melhorado.

Com os dados obtidos nas categorias, percebemos as dificuldades dos profissionais em reconhecer e justificar a existência de uma rede de atendimento, como era formada, quem fazia parte e a reflexão acerca da compreensão sobre a rede, emergindo a subcategoria, conforme a tabela a seguir:

Tabela 1 - Percentuais das percepções dos participantes quanto à Rede de Atendimento e/ou Rede de Proteção. 


\begin{tabular}{c|c}
\hline Espaço de diálogo & $2 \%$ \\
\hline $\begin{array}{c}\text { Ineficaz } \\
\text { Rede de atendimento e Rede de proteção são } \\
\text { diferentes }\end{array}$ & $4 \%$ \\
\hline São serviços & $46 \%$ \\
\hline Não sei & $8 \%$ \\
\hline Não informou & $12 \%$ \\
\hline TOTAL & $16 \%$ \\
\hline
\end{tabular}

Fonte: arquivo próprio

Chamou a atenção que $46 \%$ dos profissionais entendem que existem duas redes: uma de atendimento, que prestaria o atendimento inicial e uma de proteção, que seria mais especializada. De acordo com algumas falas, podemos confirmar o que mencionamos: "rede de atendimento é dado na primeira vez que a vítima é abusada. Rede de proteção é o acolhimento e a orientação psicológica" (Lavanda roxa ${ }^{5}$ ); "rede de atendimento é aquela que dá o suporte para que o vinculo não seja rompido, já a rede de proteção é cuidar e dar o suporte quando a vulnerabilidade já é um fato prejudicial" (Hortênsia rosa). Os percentuais sobre a existência de uma rede de proteção apontam que: $32 \%$ consideram que não existem, $30 \%$ consideram que existem, $6 \%$ não sabem e $32 \%$ não informaram. Percebemos que o número de não informantes nesta questão foi elevado, apresentando o desconhecimento ou a dúvida em relação à rede de atendimento.

No que diz respeito à composição da rede de atendimento, percebemos que, apesar de alguns profissionais considerarem a existência de uma rede, não sabem indicar como esta rede é composta, conforme acompanhamos com o relato a seguir: "não sei bem como se configura, porém, tenho certeza de que necessite de maior investimento por parte do governo" (Jasmim rosa). Além do desconhecimento, ainda existem dúvidas em relação à composição da rede o que é coerente com o resultado da análise da primeira fase desta pesquisa, quanto ao fluxo do atendimento à criança e ao adolescente vitimizado. O que é confirmado quando uma participante questiona: “através do Sentinela?” (Lírio dourado), como se fosse possível uma única instituição, ou mesmo duas compor uma rede. Os dados mostram que, apenas três profissionais acreditam na existência de uma rede e informaram a composição desta rede com mais

\footnotetext{
${ }^{5}$ Usamos nomes de flores para preservar a identificação dos participantes, que tinham a oportunidade de escolher o nome da flor, que gostariam de serem identificados ao preencher o Termo de Consentimento Livre e Esclarecido.
} 
de duas instituições: CT, CREAS, MP, Delegacias, as Casas de Acolhida, o Rede Família, a Prefeitura e a Casa de Passagem. Os demais profissionais indicam apenas uma instituição ou o CT ou o CREAS.

Constatamos algumas preocupações, no que tange aos desafios que enfrentam a rede de atendimento as vítimas de abuso social, como: a necessidade de melhorias, além de capacitação dos recursos humanos que somam $22 \%$, o que denota a importância de realizar mais cursos de formação para dar suporte aos profissionais. Outros $28 \%$ abordam elementos de infraestrutura e recursos humanos, o que casualmente soma a metade dos participantes. Podemos dizer que as outras categorias correspondem a: $18 \%$ atendimento do abusador, $10 \%$ humanização e $22 \%$ a obtenção do retorno das instituições.

Quanto à percepção dos profissionais sobre o medo ou receio em relação à denúncia, ainda constitui-se um desafio social a ser superado em rede, já que $32 \%$ não informaram, ou seja, nada apontaram como possibilidade de melhoria devido à dificuldade do comprometimento. Os outros $68 \%$ preferiram não opinar. Quanto às mobilizações preventivas, 100\% dos participantes reconhecem a importância de ações de prevenção para os casos de violência sexual contra as crianças e os adolescentes e que estas possam ser implementadas, através do conhecimento prévio sobre as temáticas do programa de intervenção. Reiteram que, apesar de trabalharem com vitimas de abuso, existe a sensação de impotência, o que demonstra a falta de preparo que, muitas vezes, paralisa o profissional diante da complexidade da situação e certamente compromete a qualidade do atendimento destes casos.

Quanto aos conteúdos abordados, mencionamos brevemente o que foi tratado nos módulos: o Módulo I trabalhou com noções básicas sobre os Direitos Humanos, focando nas violações dos direitos das crianças e dos adolescentes. Foram referidas definições de abuso sexual infantil e os indicadores desta modalidade de violência. Os relatos durante as discussões apontaram o abusador como um doente, um ser desprezível, que mereceria uma pena máxima pelo crime cometido. Na intenção de mobilizarmos uma reflexão acerca dos apontamentos direcionamos as discussões, motivando a (re)pensarem acerca da complexidade que envolve a relação entre os envolvidos na prática abusiva (PELISOLI, TEODORO; DELL'AGLIO, 2011; 
PELOSOLI, 2008). Principalmente, salientando a importância de um trabalho com o abusador, já que a realidade é um sistema prisional que não reabilita um indivíduo para o retorno à sociedade (MOURA; KOLLER, 2008).

A proposta do módulo II foi trabalhar as diferenças entre incesto, pedofilia e abuso sexual. Percebemos visões um tanto preconceituosas em se tratando da vítima ser adolescente: "as meninas andam quase nuas" (Rosa vermelha); "elas pedem" (Tulipa verde); "atendemos muitas adolescentes grávidas" (Girassol amarelo). A conclusão das discussões levou todos a ponderar sobre a necessidade de se ter um olhar mais cuidadoso nestes casos, e que estamos vivendo em um contexto midiático e global que expõe a mulher. Entretanto, tal fato não pode justificar qualquer ato de violência (FURNISS, 1993; FLORENTINO, 2015).

No módulo III foram trabalhadas as questões legais (CF, CP e o ECA), onde os profissionais apontaram a importância da notificação, do acompanhamento, de espaços de diálogo entre todos os setores para discutir os casos em conjunto, e não somente entre as equipes de cada serviço. Isto confirmou-se com a fala de uma das participantes: "é difícil, mas não impossível, com a ajuda de todos da sociedade, ou seja, todos precisam estar mobilizados e comprometidos" (Margarida branca). No Módulo IV estabelecemos um diálogo sobre Família e violência, onde foram estudadas as causas e consequências do abuso intrafamiliar e a importância de um trabalho com as famílias. Sobre este tema, os profissionais manifestaram suas dificuldades em trabalhar com as famílias, principalmente nos casos de abuso intrafamiliar, o que confirma a necessidade de um trabalho articulado da rede de atendimento.

No módulo $\mathrm{V}$ trabalhamos a notificação como forma de proteção à criança e ao adolescente. Tivemos manifestações, contrárias acerca da denúncia, conforme podemos acompanhar a seguir: "O problema é quando a gente denúncia e não dá em nada" (Cravo vermelho). A fala desta profissional foi utilizada para promover uma reflexão acerca do papel do profissional e da influência da sociedade, enquanto também responsáveis em proteger as crianças e os adolescentes. Constituindo-se a notiticação numa forma de proteção (PIETRO, 2007; PIETRO; YUNES, 2007). Quanto à rede de proteção, os profissionais apontam que não funciona, é deficiente e não cumpre com o seu papel, o que possibilitou concluir em conjunto com os participantes que não temos 
uma rede de proteção, e sim serviços que precisam se articular e aprender a atuar em rede.

No módulo VI refletimos acerca do papel do profissional e continuamos a reflexão acerca da rede e da atuação do profissional, enquanto um Educador Social e Ambiental. Ao compartilharmos conhecimentos, iam emergindo das discussões alguns questionamentos como: de que forma era possível implementar uma rede de proteção? Esta era a pergunta chave entre os participantes, e ainda, qual o nosso papel enquanto um Educador Social e Ambiental? Os questionamentos foram ao encontro das possibilidades de melhoria apresentadas na primeira fase deste estudo, conforme justificamos com alguns relatos: "mais comunicação entre os serviços" (Cravo Amarelo); "conhecimento do que cada instituição faz" (Margarida), "mais comprometimento do profissional" (Flor do Campo) e "mais capacitações como esta" (Orquídea).

O último encontro foi dividido em dois grandes momentos: o primeiro foi $\mathrm{o}$ desenvolvimento do módulo VII, a elaboração de um plano de ação e o módulo VIII, a aplicação de um plano de intervenção. O plano de intervenção versou sob o tema da capacitação e pela dificuldade expressa em vários momentos da construção deste trabalho. Pudemos notar ainda, que as ações propostas foram realizadas em diferentes contextos: na escola, na família e na comunidade, o que denotou indícios de um olhar ecológico para o fenômeno do abuso, minimizando então, a ótica de "trabalho isolado", detectado na primeira fase do estudo.

Os temas permearam a problemática da violência no âmbito das relações familiares, assim como, um melhor conhecimento acerca do Estatuto da Criança e do Adolescente, o que, conforme os participantes, seria uma oportunidade para compreender e lidar com a complexidade do abuso sexual, contando com a atuação de uma rede de proteção. Dentre estas considerações, ressaltamos a necessidade do coletivo entre/com a rede, para que seja uma teia de múltiplos nós e que a cooperação, o diálogo e a participação entre/com todos os profissionais seja o fio propulsor. O que mais uma vez reitera que o "olhar ecológico" foi semeado, pois, além de todos os planos de intervenção indicar a participação de várias instituições, mobilizou e inquietou sobre a importância da atuação da rede. 


\section{CONSIDERAÇÕES FINAIS}

Estudar o contexto sócio-ecológico-ambiental do atendimento das instituições que recebem a criança e/ou adolescente e a família foi primordial, não só para compreender como o atendimento é realizado, mas, também, como estes profissionais percebem as crianças e/ou adolescentes, as famílias e os abusadores. Os profissionais revelaram-se incapacitados para atuarem com esta modalidade de violência e continuavam, às vezes, por anos, desconhecendo o fluxo de atendimento de seu próprio serviço. Nestas situações, percebemos acomodação, o que coaduna ao mencionarem que precisavam de pessoas mais capacitadas, já que não era papel delas articular e organizar ações para o atendimento das crianças e dos adolescentes vítimas de abuso sexual. Falavam que era função da rede de atendimento, como se não fizessem parte dessa atuação, que deveria ser conjunta para fortalecer os nós que integram cada setor e que, juntos são e compõem a rede.

Os profissionais compreendem que existe uma rede de atendimento, mas que é frágil e não é efetiva, tendo em vista as respostas que foram apresentadas desde a primeira fase deste estudo. As instituições participantes apresentam uma ideia de rede, mas uma rede que não atua de forma protetiva para os casos de abuso sexual contra as crianças e/ou adolescentes, uma vez que, os próprios profissionais apresentam um sentimento de impotência diante das situações abusivas. As crianças, os adolescentes e as famílias são as vítimas potenciais desta modalidade de violência, tão perversa que assombra tantos lares em diferentes partes do planeta.

Pudemos notar que os profissionais entendem a rede de atendimento e a rede de proteção como diferentes e que cada uma teria suas especificidades: a primeira com o atendimento e a segunda com o atendimento especializado. Enfim, a problemática foi evidenciada na carência e limitação de muitos setores e segmentos da nossa sociedade, que ainda não conseguem desenvolver um trabalho articulado e em rede. Entendemos que o homem, enquanto sujeito social integrado ao meio, necessita (re)pensar suas relações e ações dentro de uma sociedade que exige mais humanidade e solidariedade para além do cuidado, mas pelo/com o respeito à dignidade da pessoa humana.

A necessidade de formação permanente justifica-se e ganha mais amparo quando é mobilizada coletivamente, para que seja efetiva e em rede. Assim, os nós precisam ser 
firmes e, para formar um tecido forte e imutável, é necessário engajamento ao buscar e estar em formação permanente. Por isso, foi uma das propostas do programa, propor ao profissional um olhar sistêmico e ecológico, buscando uma comunicação entre os setores.

Quanto às medidas de prevenção, observamos a necessidade das famílias estarem atentas, promovendo espaços de diálogos com as crianças sobre os riscos que podem estar sujeitos. Somados à importância do papel da educação e da capacitação permanente, defendemos a promoção de mais espaços grupais de reflexão e ação, que sejam realizados dentro de espaços formais e não formais de educação, sendo mediados pelo modelo experiencial, já que são construídos com e não para os profissionais.

A participação durante a aplicação dos módulos foi constante, revelando a necessidade de mais espaços dialógicos, o que foi dado início com o programa. A construção dos planos de intervenção fez com que os profissionais buscassem ações possíveis de serem concretizadas e implementaram a formação de uma rede de proteção pelas/com nas parcerias nas atuações. Neste sentido, o programa foi direcionado para que os profissionais fossem agentes multiplicadores e potencializadores de proteção.

Este, na verdade, não foi o fim de um trabalho, mas o início de outros tantos, tendo em vista que este estudo contribuiu para pensar mais humanamente e com vistas à proteção das crianças e/ou adolescentes, que são membros da sociedade, e como tais, merecem e devem ser tratados como cidadãos, tendo seus direitos respeitados. Assim, compreendemos a necessidade da formação de educadores sociais e ambientais, indivíduos revestidos de uma compreensão ampla e concreta do fenômeno, bem como despidos de teorias implícitas e negativas. Na medida em que esta compreensão for apropriada por todos os atores envolvidos, será possível um trabalho que possa ser construído em uma rede de proteção.

\section{REFERÊNCIAS}

AZEVEDO, Maria Amélia; GUERRA, Viviane Nogueira. Crianças Vitimizadas: a síndrome do pequeno poder. São Paulo: Iglu, 1989. 211 p.

BRASIL, Estatuto da Criança e do Adolescente, 2017. Disponível em: <http://www.planalto.gov.br/ccivil_03/leis/L8069.htm>. Acesso em abr. 2017.

BRONFENBRENNER, Urie. Bioecologia do Desenvolvimento Humano: tornando os seres humanos mais humanos/BRONFENBRENNER, Urie. Tradução: 
CARVALHO, André.; Revisão técnica: KOLLER, Silvia Helena.- Porto Alegre: Artmed, 2011. 310p.

BRONFENBRENNER, Urie. A ecologia do desenvolvimento humano: experimentos naturais e planejados. Porto Alegre: Artes Médicas, 1996. 267p.

BRONFENBRENNER, Urie.; MORRIS, Pamela. The ecology of developmental processes. In DAMON, W. (Org.). Handbook of child psychology. v. 1. New York: John Wiley Sons, 1998. 993-1028p.

CARVAlHO, I. M.; ALMEIDA, P. H. Família e proteção social. Perspec., v.17, n.2, São Paulo abr./jun. 2003.

DIAS, G. F. Educação ambiental: princípios e práticas. 5. ed. São Paulo: Gaia, 2004. $551 \mathrm{p}$.

DUARTE, F.; KLAUS, F. Redes Urbanas. In.: DUARTE, F; QUANDT, C.; SOUZA, Q. O Tempo Das Redes. [s. 1.]: Editora Perspectiva S/A, 2008. p. 156.

FALEIROS, Vicente de Paula. Abuso sexual de crianças e adolescentes: trama, drama e trauma. In.: COSTA, Liana Fortunato; ALMEIDA, Tania Mara Campos. Violência no cotidiano: do risco à proteção. Brasília: Universa: Liber Livro, 2005. 337p.

FARAJ, Suane Pastoriza Faraj; SIQUEIRA, Aline Cardoso. A notificação da violência, o atendimento psicológico e a rede de proteção da criança e do adolescente: o olhar de profissionais do sistema de garantia de direitos, 2014. 156p. Dissertação, Curso de Mestrado do Programa de Pós-Graduação em Psicologia da Saúde, da Universidade Federal de Santa Maria, RS.

FARAJ, Suane Pastoriza; SIQUEIRA, Aline Cardoso; ARPINI, Dorian Mônica. Rede de proteção: o olhar de profissionais do sistema de garantia de direitos. Trends in Psychology / Temas em Psicologia - 2016, Vol. 24, no 2, pp. 727-741. Disponível em <http://pepsic.bvsalud.org/pdf/tp/v24n2/v24n2a18.pdf> Acesso em maio de 2017.

FLORENTINO, Bruno Ricardo Bérgamo. As possíveis consequências do abuso sexual praticado contra crianças e adolescentes. Fractal: Revista de Psicologia, v. 27, n. 2, pp. 139-144, maio-ago. 2015. Disponível em: <http://www.scielo.br/pdf/fractal/v27n2/1984-0292-fractal-27-2-0139.pdf> Acesso em fev. 2017.

FURNISS, Tilman. Abuso Sexual da Criança: Uma abordagem Multidisciplinar, Manejo, Terapia e Intervenção Legal Integrados. Tradução: VERONESE, Maria Adriana Veríssimo. Porto Alegre: Artes Médicas, 1993. 337p.

HABIGZANG, Luísa; KOLLER, Sílvia; AZEVEDO, Gabriela Azen; MACHADO, Paula Xavier. Abuso sexual infantil e dinâmica familiar: aspectos observados em processos jurídicos. Psicologia: Teoria e Pesquisa. Vol. 21 no. 3, pp. 341- 348. Brasília. Set/dez. 2005. Disponível em: <http://www.scielo.br/pdf/ptp/v21n3/a11v21n3.pdf> Acesso em jan. 2017.

HOHENDORFF, Jean Von; SILVA, Roberta Salvador; ANDRADE, Rosiane de; HABIGZANG, Luísa Fernanda; KOLLER, Silvia Helena. Adaptação e Avaliação de uma Intervenção Cognitivo-Comportamental para Meninos Vítimas de Violência Sexual. Psychology/Psicologia Reflexão e Crítica, 27(3), pp. 424-433, 2013. Disponível 
em: 〈http://www.scielo.br/pdf/prc/v27n3/0102-7972-prc-27-03-00424.pdf>. Acesso em fev. 2017.

MACHADO, C. R. S.; CALLONI, H.; ADOMILLI, G. Olhares, pensares e fazeres sobre e na educação ambiental: reflexões sobre/desde os fundamentos ao campo atual brasileiro. Ambiente \& Educação ISSN- 1413-8638, v. 21, n. 1, p. 3-25, 2016. Disponível em: < file:///C:/Users/Eli/Downloads/6252-17925-1-PB\%20(1).pdf>. Acesso em fev. 2017.

MÁIQUEZ, María Luisa, RODRIGO, Maria José, CAPOTE, Carmen; VERMAES, Ignace. Aprender en la vida cotidiana. un programa experiencial para padres. Madrid: visor, 2000. 275 p.

MARQUES, M. S.; MAIO, J. S. M. O trabalho em rede e o depoimento em juízo: implicações ao atendimento de uma criança que sofreu abuso sexual e o cuidado com o profissional. In: LEAL, M. L. P.; LEAL, M. F. P.; LIBÓRIO, R. M. C. (orgs.) Trafico de Pessoas e Violência Sexual. Brasilia: VIOLES/SER/Universidade de Brasília, 2007. 274 p

MARTíN, Juan. Carlos. AMAYA, Raquel; RUIZ, Rodrigues; ÁLVAREZ, Blanco. Programas de educación parental. Intervención psicosocial, v. 18, n. 2, 2009, p. 121-133.

MARTÍN, Juan Carlos. Evaluación del programa de apoyo personal y familiar para familias en situación de riesgo psicosocial. Tese de doutorado [não publicada]. Universidad de La Laguna, Tenerife, Espanha, 2005.

MOURA, Andreia da Silva; KOLLER, Silvia Helena. A criança na visão de homens acusados de abuso sexual: um estudo sobre distorções cognitivas. Psico-USF, v. 13, n. 1 , p. 85-94, jan./jun. 2008. Disponível em http: <http://www.scielo.br/pdf/pusf/v13n1/v13n1a11.pdf>. Acesso em: dez. 2016.

PELISOLI, Cátula da Luz. Entre o público e o privado: Abuso sexual, família e rede de atendimento. 2008. 111f. Dissertação- Curso de Pós-Graduação em Psicologia, Instituto de psicologia, Universidade Federal do Rio Grande do Sul. Instituto de Psicologia.

PELISOLI, Cátula da Luz; TEODORO, Maycoln. Lêoni; DELL'AGLIO, Débora Dalbosco. A percepção de família em vítimas de abuso sexual intrafamiliar: Estudo de caso. Arquivos Brasileiros de Psicologia, v. 59, n. 2, pp. 112-121, 2011. Disponível em: <http://146.164.3.26/seer/lab19/ojs/viewarticle.php?id=159, 2007>. Acesso em: dez. 2016.

PIETRO, Angela Torma. A denúncia de abuso sexual no ambiente escolar: o estudo de uma proposta de intervenção para professores do Ensino Fundamental, 2007. 117f. Dissertação de Mestrado Curso de Pós-Graduação em Educação Ambiental, Instituto de Educação, Universidade Federal do Rio Grande, Rio Grande, RS.

PIETRO, Angela Torma. A ecologia da violência sexual contra crianças e adolescentes: redes de proteção e uma intervenção positiva, 2013. 197f. Tese de Doutorado. Curso de Pós-Graduação em Educação Ambiental, Instituto de Educação, Universidade Federal do Rio Grande, Rio Grande, RS. 
PIETRO, Angela Torma; YUNES, Maria Angela Mattar. O ato da denúncia de abuso sexual contra crianças e adolescentes no ambiente escolar. In: LEAL, Maria Lucia Pinto e LEAL, Maria de Fatima; Libório, Renata Maria Coimbra Tráfico de Pessoas e Violência Sexual. (pp. 167-190). Brasília: VIOLES/SER/ Universidade de Brasília, 2007. 274 p.

PIETRO, Angela Torma; YUNES, Maria Angela Mattar; LIMA, Eliane Duarte. Programa de intervenção psicoeducacional para professores: A escola como espaço de proteção em casos de abuso sexual. Revista Electrónica de Enseñanza de las Ciencias Vol. 13, $\mathrm{N}^{\mathrm{o}}$ 1, pp. 1-17, 2014. Disponível em <http://reec.uvigo.es/volumenes/volumen13/REEC_13_1_1_ex697.pdf>. Acesso em jan. 2017.

PINCOLINI, Ana Maria Franchi. Bem-estar subjetivo em famílias com histórico de abuso sexual intrafamiliar. Gerais, Rev. Interinst. Psicol. vol.5 no.1, pp. 3-22. Juiz de fora jun. 2012.

Disponível

em:

http://pepsic.bvsalud.org/pdf/gerais/v5n1/v5n1a02.pdf> Acesso em jan. 2017.

SANTOS, Silvia Renata Magalhães Lorbello Borba. Menina, mulher, filha, mãe? A gravidez decorrente de violência sexual, 2013, p. 185. Tese- Programa de PósGraduação em Psicologia Clínica e Cultura, Instituto de Psicologia, Universidade- UnB, de Brasília- Distrito Federal.

SANTOS, J. E.; SATO, M. (orgs.) A contribuição da educação ambiental à caixa de Pandora. São Carlos: Rima, 2001 p.34.

SOUZA, E. R.; ASSIS, S. G. A.; ALZU, F. C. V. Estratégias de atendimento aos casos de abuso sexual infantil: um estudo bibliográfico. Rev. bras. saúde matern. infant., Recife, v. 2, n. 2, p. 105-116, maio/ago. 2002.STRAUSS, Anselm; CORBIN, Juliet. Basics of qualitative reserch: Grounded theory procedures and techniques. London: Sage, 1990.

STRAUSS, A.; CORBIN, J. Basics of qualitative reserch: Grounded theory procedures and techniques. London: Sage, 1990.

YUNES, Maria Angela Mattar. Resiliência familiar e parentalidade positiva: a aplicação do modelo experiencial em Programas de Educação Parental. Projeto de pesquisa submetido ao CNPq - Edital para concessão de Bolsa de Produtividade, 2012.

YUNES, Maria Angela Mattar; MIRANDA, Angela Torma; CUELLO, Sandra Eliane Sena Um olhar ecológico para os riscos e oportunidades. In: KOLLER, Silvia. (org.). Ecologia do desenvolvimento humano: pesquisa e intervenção no Brasil. São Paulo: Casa do Psicólogo, 2004. Pp. 193- 214.

YUNES, Maria Angela Mattar; SZYMANSKI Heloisa. Grounded-theory \& Entrevista Reflexiva: uma associação de estratégias metodológicas qualitativas para uma compreensão da resiliência em famílias. In.: GALIAZZI, Maria; FREITAS, José Vicente (orgs.) Metodologias emergentes de pesquisa em educação ambiental. Ijuí: Editora Unijuí, 2005. Pp. 115-134. 